\title{
An assessment of measures for the prevention of the origin and consequences of a selected group of exceptional events in a territorial unit
}

\author{
J. Betáková ${ }^{1}$, R. Zeman ${ }^{1}$, T. Pavlenko² \& J. Dvorský ${ }^{2}$ \\ ${ }^{1}$ Institute of Technology and Business in České Budějovice, \\ Czech Republic \\ ${ }^{2}$ Faculty of Security Engineering, University of Žilina, Slovak Republic
}

\begin{abstract}
Under the influence of society-wide developments there is an immediate need for an imperative solution to the question of broad based integrated planning of territorial development with a synergistic effect. Spatial management creates the foundations for the harmonization and functional use of a territory. Its development is negatively influenced by exceptional events originating on the given territory. The incorporation of preventive measures into strategic documents of spatial management provides an increase in security for the territorial unit. This paper focuses on the assessment of specific preventive measures for the origin and minimization of the consequences of exceptional events. Particular attention is paid to a selected group of exceptional events, namely natural disasters. The aim of the paper is, on the basis of suitably set criteria, to designate measures through the method of multi-criteria decision-making. The purpose of selecting the most suitable measures with the use of the multi-criteria decision-making method is to see them put them into practice and directly incorporated into strategic territorial planning documents.

Keywords: territorial plan, multi-criteria decision-making, exceptional event, natural disaster.
\end{abstract}




\section{Introduction}

Under the influence of overall social developments, it is clear that there is an immediate need for urgent solutions to the current issues of broad based integrated spatial development planning with a synergistic effect. Spatial management creates conditions for the harmonization of land use. The development of an area is negatively affected by crisis phenomena which occur in a particular territory. The security of a territorial unit increases when preventive measures are incorporated into zoning plans. In this paper attention is drawn to the current situation with regards to territorial planning documents and points to the lack of security which impacts on the sustainable development of cities and towns. Sustainable development is closely dependent on the interconnection between a municipality/city and its environment and the subsequent development of perceptions in relation to the problems and challenges of humanity. The security of the selected area is threatened by various crisis phenomena that occur in the territory. By determining and selecting specific crisis phenomena which can threaten the selected area, it is possible to propose preventive measures which will increase the level of security for the given territory.

\section{Current situation with regards to territorial planning documents}

In the Slovak Republic land planning deals with all aspects of our environment. This includes the building of residences, infrastructure, and environmental elements. The basic instrument of urban planning is a territorial plan which is formed at different levels - regional territorial plan, land use plan of the municipality and zoning plan. At present, these plans must adhere to clear rules and provide order in the area. They focus on fair and balanced development. They do not provide an exact template for how residential buildings or groups of buildings are placed within the design. Rather, they provide a framework for developments, both wanted and unwanted, based on the principles and limits set. A concrete master plan addresses the spatial arrangement and functional use of land. As part of the harmonization of these activities, the emphasis is placed on caring for the environment, achieving ecological balance and ensuring sustainable development. Attention is also paid to the careful use of natural resources and the preservation of civilization and cultural values. The main task of a master plan is to determine the limits of land use, focusing on the functional and spatial arrangement of reconstruction and cultural interventions. The plan must include the designation of protected territory, the premises for this, and the changes required with regards to spatial and technical implications. The roles in developing land-use plans, land-use planning documents and land planning documentation are defined in Act No. 50/1976 Coll. of the Federal Assembly of the Czechoslovak Socialist Republic on Land-use Planning and Building Order (Building Act). Land-use planning documents are documents discussed and ordered under the Building Act. It is a set of data for the purpose of land use planning which incorporate methods of spatial planning. The documentation is processed in order 
to verify which problems need to be solved in the area, to obtain information about the area and to enhance solutions to the individual components of settlement [1]. Such planning documents and land planning documentation usually have one major shortcoming - they insufficiently incorporate preventive measures against emergency events. These preventive measures are not required under the Building Act. As a result, the issue of safety in the processing of land documentation remains in the background. This is unfortunate because there is a lack of emphasis on risk management which is part of prevention and an essential element of crisis management. The safety and protection of the population is only marginally addressed in Act No. 42/1994 Coll. on the Civil Protection of the Population. In Section 4, paragraph 3 it states: "When processing the master plan, the authorities in cooperation with local offices must determine the scope of compulsory constructions for civil protection". According to Act No. 42/1994 Coll. on Civil Protection, a territory must protect against emergencies of different characters. In Section 3, paragraph 2 of Act No. 42/1994 Coll. on the Civil Protection of the Population, the term emergency means natural disasters, accidents, second degree public health emergencies or terrorist attack [2]. The need to incorporate preventive measures into land-use planning documentation in the Slovak Republic was incorporated in amendments to the Building Act. The amendments set forth the future obligation of villages, towns and cities to develop master plans. These obligations were set according to population size:

a) over 1,000 inhabitants by the end of 2020;

b) from 500 to 1000 inhabitants by the end of 2027 ;

c) up to 500 inhabitants by the end of 2034 [1].

\section{Survey methodology and analysis of safety enhancing preventive measures}

In the present study, the focus is on preventive measures that can be incorporated into spatial planning documentation. The research sample included 120 respondents. The respondents were those people responsible for spatial planning in the municipalities in the Trencin region. The research was conducted between March and June, 2015. The individual local authority representatives for urban planning evaluated selected natural disasters on a scale of 1 to 10 . The value 1 represented the smallest threat to a community, and the value 10 the greatest threat to a community. The survey was conducted by means of a questionnaire which was sent electronically. Based on the processed questionnaire, natural disasters were chosen which specifically threaten the safety of the majority of the selected areas. The aim of this study was to choose the most appropriate preventive measures that increase the safety of the area and reduce the negative consequences of natural disasters. The basic framework for examining this issue forms a bond between the demands on territorial planning documentation to improve safety and the use of possible preventive measures in the selected areas. Part of the objective of the survey was to determine the necessary criteria under which the selection of preventive measures should be carried out [3]. 
Logical methods of research, the multi-criteria decision-making method, and the mathematical and statistical "analysis of variance" were applied in the article. The processing of the "analysis of variance" is numerically intensive and was therefore implemented with the support of the statistical software STATGRAPHICS CENTURION XVII. The analytic-synthetic method was used to examine various preventive measures and land planning documentation. The actual processing was divided into the following stages:

- $\quad$ analysis of planning documentation and practical experience compatible with the implementation of selected tools of spatial management and spatial impact on the development of settlement structures;

- calculation of selection characteristics (mean, variance) for the identified natural disasters on the basis of the assessments of mayors from settlements in the Slovak Republic as part of this case study;

- determination of the suitability of use of the parametric or non-parametric test of the mathematical method "analysis of variance" for the assessment of natural disasters given the conditions imposed on their implementation;

- testing of the mean values of the identified natural disasters in selected groups using the parametric F-test and non-parametric Kruskall-Wallis test;

- determination of whether the mean values of the mayors' assessments of the identified natural disasters in groups according to the population criteria, are homogenous or comparable;

- evaluation of preventive measures within the context of sustainable development through the use of a modified decision matrix method (Forced Decision Matrix Method - FDMM);

- summarization of conclusions for the practical application of a progressive approach to the assessment of the development potential of settlement formations [4].

The comprehensive research on incorporating preventive measures into urban planning documentation was conducted within the framework of project $K E G A$ No. 005 DTI-4-2014 Sectorial integration of spatial impacts of the safety management of environmental risks. In this study, the focus is on natural disasters in which there is an undesirable release of accumulated energy or materials as a result of adverse forces of nature. This includes hazardous substances or destructive factors that can have a negative impact on life, health or property. An area affected by the effects of a natural disaster is characterized by the displacement of a large number of people, destruction of and damage to buildings, industrial facilities, bridges, disruption of transport, destruction of cultural monuments and protected natural formations. After the effects of a natural disaster the affected territory may also be flooded, thereby affecting a large number of animals and resulting in deteriorating health conditions. These negative effects help us to categorize natural disasters as follows: 
1. floods;

2. hail storms;

3. very strong winds;

4. landslides;

5. heavy snow and avalanches;

6. extensive icing;

7. earthquakes [5].

The goal of applying the statistical method of "variance analysis" was to find out whether the assessment of the threat an identified disaster poses, as determined by the competent people for planning within a municipality planning in relation to population size, is comparable or it has statistically significant differences. The competent people in the area of spatial planning were divided into three groups. The first group consisted of municipalities with populations of less than one thousand inhabitants. The second group consisted of municipalities with a population of 1001-2000 inhabitants. The last group covered municipalities with a population greater than 2000 inhabitants. According to the criterion of population, it was determined that a statistically credible sample would be 40 people from each group. Firstly, the basic statistical characteristics of the evaluation of natural disasters were calculated. In all three groups floods and flooding were considered to pose the greatest threats. Landslides and hail storms also received a high average assessment. To carry out a parametric or nonparametric "analysis of variance" test requires the condition of homoscedasticity to be met i.e. the identity of variances of natural disasters in each group and the probabilistic model of the usual assessment distribution in each group. Homoscedasticity was verified by using the Bartlett's test. For all the selected groups the resulting $p$-value was higher than the pre-set significance level of 0.05 for all natural disasters. The condition of homoscedasticity was therefore met. The condition of the normal distribution of values was done by the Pearson $\mathrm{x}^{2}$ test. From the results of the Pearson $\mathrm{x}^{2}$ test, at a significance level of 0.05 , it can be concluded from the resulting p-values of assessment of natural disasters that hail storms (2), very strong winds (3) and earthquakes (7) did not meet the probability model of normal distribution. For these natural disasters the non-parametric Kruskall-Wallison test was used. For the other natural disasters - floods (1), landslides (4), heavy snow and avalanches (5) and extensive icing (6) - the parametric F-test was used. The results are given in Tables 1 and 2 [6].

Table 1: Parametric F-test of selected natural disasters.

\begin{tabular}{|c|c|}
\hline $\begin{array}{c}\text { Selected natural } \\
\text { disasters }\end{array}$ & $\begin{array}{c}\text { F-test } \\
\text { (p-value) }\end{array}$ \\
\hline 2. & 0.019 \\
\hline 3. & 0.000 \\
\hline 7. & 0.001 \\
\hline
\end{tabular}


Table 2: Non-parametric Kruskall-Wallis test of selected natural disasters.

\begin{tabular}{|c|c|}
\hline $\begin{array}{c}\text { Selected natural } \\
\text { disasters }\end{array}$ & $\begin{array}{c}\text { Kruskall-Wallisov } \\
\text { test (p-value) }\end{array}$ \\
\hline 1. & 0.401 \\
\hline 4. & 0.307 \\
\hline 5. & 0.014 \\
\hline 6. & 0.038 \\
\hline
\end{tabular}

The results of the analysis of variance for the assessment of selected natural disasters identified by the competent authorities for the area of spatial planning in the Slovak Republic from Table 1 and Table 2 show that:

- with $95 \%$ reliability, the statistical assumptions about the homogeneous or comparable evaluation by the people responsible for spatial planning, according to the selected population criteria, is accepted with regards to floods and landslides.

- with 95\% reliability, the homogeneous statistical assumptions or comparable evaluation by the people responsible for spatial planning, according to the selected population criteria, cannot be accepted for other natural disasters.

The survey results indicate that there are differences in the assessment by the people responsible for spatial planning in communities for landslides and floods. For negative effects of all these natural disasters it is possible to propose preventive measures. This paper focuses on the survey results, on the measures that can and should be taken against floods and landslides. These natural disasters are based on statistical processing per the most commonly occurring natural phenomena.

Floods are a natural phenomenon which is almost impossible to prevent. With technical and organizational measures it is possible in some cases to prevent or substantially reduce the damage. The method implemented for the protection of a selected area depends on what causes the floods, the economic importance of the area and the size of the area to be protected. Figure 1 shows which flood protection measures can be taken [5].

Agricultural and forestry measures - the primary function of these measures is to increase the retention of moisture in the basin and to reduce runoff. In severe cases additional flood protection is provided by technical measures. By adjusting flows, the flow route is regulated. In order to do so a suitable longitudinal profile and sufficient flow profile within the channel need to be created. The main aim of flow adjustment is to protect the habitat, communications, agricultural areas and to stabilize the riverbed. There are a multitude of ways how to adjust flows e.g. hardening the bottom of a riverbed, (non-)vegetative compaction of river banks, or combinations thereof. There are two forms of protective channel which can be used as a preventive measure, namely retaining channels or relieving ones. Retaining channels are designed to collect torrential rainwater which flows from 


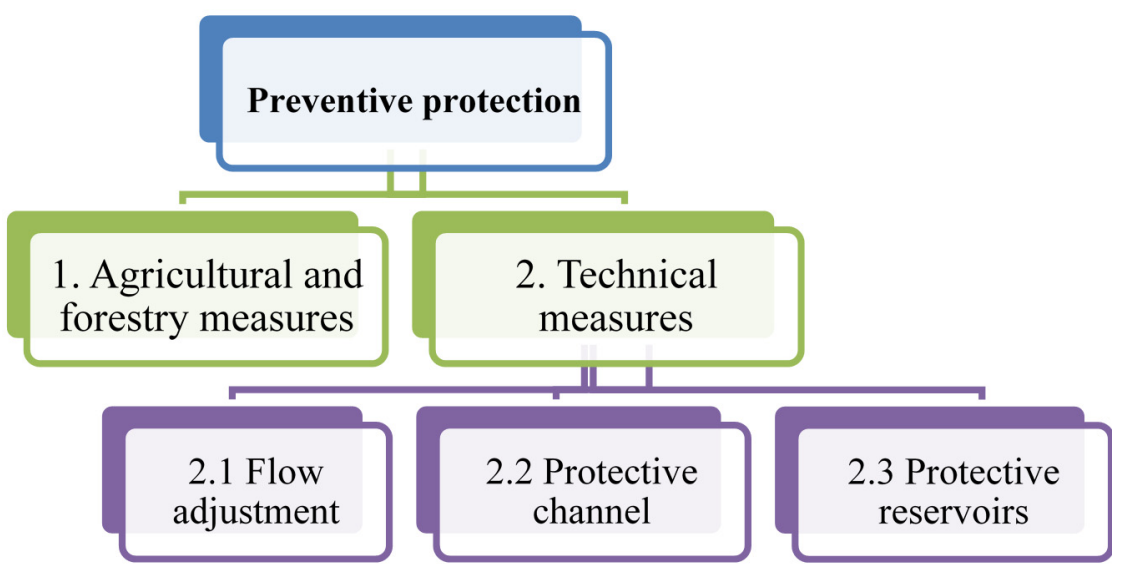

Figure 1: $\quad$ Preventive protection measures against floods.

surrounding ridges and hills. Relieving channels are used to discharge that part of torrential rainwater which could potentially overflow into a protected area. Protective reservoirs have proved to be an effective preventive measure when mapping out the complex tasks associated with flood management [5].

Landslides are another very significant natural disaster threatening the security of territorial units. A landslide is a mass movement of soil due to gravitational effects on mountains and slopes. Landslides occur for a variety of reasons. They destroy the human environment, destabilize linear buildings, damage roads, highways, railways, pipelines, power lines and forests. Drainage of a potential landslide or existing landslide area is an effective preventive measure. On the basis of the comprehensive examination of the survey it is suggested that the following precautions are undertaken (see Figure 2) [5].

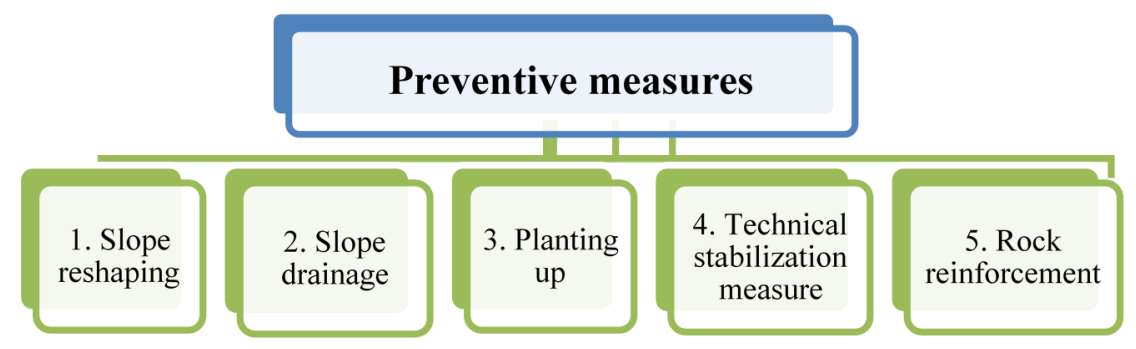

Figure 2: Preventive measures.

The adjustment of a slope must be carried out simultaneously with subsurface slope drainage. By doing so, the volume of earthworks is reduced. The slope adjustment can involve moderating a slope, loading embankments and/or slope easing. The planting of forest vegetation fulfils two objectives with regards to slope stabilization. It dries out the surface layer and mechanically fixes the 
landslide with an array of deep roots. Frames, retaining walls, pile walls, anchoring and stabilizing ribs are the main forms of technical stabilization. Additional rock reinforcement has the ability to increase shear strength and therefore contribute to the stability of the slope [5].

By selecting the appropriate preventive measures as presented in this paper, it is possible to increase the safety of a territorial unit. In order to determine which measures are the most appropriate measures a modified method of the decision matrix will be used (FDMM - Forced Decision Matrix Method).

\section{Identifying the most appropriate measures by a modified method of the decision matrix}

Measures that can best be implemented in the territorial units of the Slovak Republic will be selected according to established criteria. The established criteria are based on the main objective of improving the safety of the territorial units. Increased levels of safety for the territorial units can be achieved through the incorporation of preventive measures into the strategic land use planning documents. In doing so, it is necessary to take into account the efficiency of a measure which is to be applied and the cost of the investment in it. A very important role in this issue is the time it takes between building or put into place a selected measure and the actual launch or coming into effective of the measure. On the basis of the objective above, criteria were established in consultation with urban planning authorities:

- $\mathrm{C}_{1}$ - the ability to integrate in spatial planning documentation;

- $\mathrm{C}_{2}$ - measure efficiency;

- $\mathrm{C}_{3}$ - financial requirements;

- $\mathrm{C}_{4}-$ the time involved in building and bringing into operation of a selected measure [7].

Through a modified method of the decision matrix (FDMM - Forced Decision Matrix Method) it is necessary to determine the weights of the individual criteria by paired comparison. For the two criteria in the paired comparison, the criterion marked " 1 " is more important for the decision, whereas the criterion marked " 0 " is less important. Table 3 lists the compared criteria and gives the determined weights for each criterion accordingly [8].

Table 3: Paired comparison of criteria.

\begin{tabular}{|c|c|c|c|c|c|c|}
\hline Criteria & C1 & C2 & C3 & C4 & Sum & Weight \\
\hline C1 & - & 0.0 & 0.0 & 0.0 & $\mathbf{0 . 0}$ & $\mathbf{0 . 0 0 0}$ \\
\hline C2 & 1.0 & - & 1.0 & 1.0 & $\mathbf{3 . 0}$ & $\mathbf{0 . 5 0 0}$ \\
\hline C3 & 1.0 & 0.0 & - & 0.0 & $\mathbf{1 . 0}$ & $\mathbf{0 . 1 6 7}$ \\
\hline C4 & 1.0 & 0.0 & 1.0 & - & $\mathbf{2 . 0}$ & $\mathbf{0 . 3 3 3}$ \\
\hline
\end{tabular}


The second step in the processing method of multi-criteria decision making is based on paired comparisons of each criterion for the individual preventive measures. The results of the pairwise comparison of the preventive measures are summarized in Tables 4 and 5. Table 4 presents the rated preventive measures that can be incorporated in the case of flooding.

Table 4: Results of the comparison of preventive measures against floods by FDMM.

\begin{tabular}{|c|c|c|c|c|c|}
\hline \multirow{2}{*}{ Criteria } & \multirow{2}{*}{ Weight } & \multicolumn{4}{|c|}{ Assessment of preventive measures } \\
\hline & & 1 & 2.1 & 2.2 & 2.3 \\
\hline C1 & 0.000 & 0.000 & 0.333 & 0.500 & 0.167 \\
\hline $\mathrm{C2}$ & 0.500 & 0.000 & 0.167 & 0.333 & 0.500 \\
\hline C3 & 0.167 & 0.500 & 0.333 & 0.167 & 0.000 \\
\hline $\mathbf{C 4}$ & 0.333 & 0.000 & 0.500 & 0.333 & 0.167 \\
\hline \multicolumn{2}{|c|}{ Weighted sum } & 0.084 & 0.306 & 0.305 & 0.306 \\
\hline \multicolumn{2}{|c|}{ Percentage of $(\%)$} & 8.4 & 30.6 & 30.5 & 30.6 \\
\hline \multicolumn{2}{|c|}{ Order } & 3. & 1. & 2. & 1. \\
\hline
\end{tabular}

On the basis of the modified method of the decision-making matrix, the most appropriate preventive measures in the event of floods is criterion 2.1 - flow adjustments, and criterion 2.3 - protective reservoirs. Table 5 presents the rated preventive measures that can be incorporated in the event of landslides.

Table 5: Results of the comparison of preventive measures against landslides by FDMM.

\begin{tabular}{|c|c|c|c|c|c|c|}
\hline \multirow{2}{*}{ Criteria } & \multirow{2}{*}{ Weight } & \multicolumn{5}{|c|}{ Assessment of preventive measures } \\
\hline & & 1. & 2. & 3. & 4. & 5. \\
\hline C1 & 0.000 & 0.200 & 0.100 & 0.000 & 0.400 & 0.300 \\
\hline $\mathbf{C 2}$ & 0.500 & 0.200 & 0.100 & 0.000 & 0.400 & 0.300 \\
\hline C3 & 0.167 & 0.400 & 0.200 & 0.300 & 0.000 & 0.100 \\
\hline C4 & 0.333 & 0.400 & 0.100 & 0.000 & 0.300 & 0.200 \\
\hline \multicolumn{2}{|c|}{ Weighted sum } & 0.300 & 0.117 & 0.050 & 0.300 & 0.233 \\
\hline \multicolumn{2}{|c|}{ Percentage of $(\%)$} & 30.0 & 11.7 & 5.0 & 30.0 & 23.3 \\
\hline \multicolumn{2}{|c|}{ Order } & 1. & 3. & 4. & 1. & 2. \\
\hline
\end{tabular}

On the basis of the modified method of the decision-making matrix, the most appropriate preventive measures for landslides are criterion 1 - slope adjustment, and criterion 4 - technical stabilization measures. 


\section{Conclusion}

In this paper - based on a survey of those people responsible for spatial planning in municipalities - we identified specific natural disasters which can seriously endanger the safety of a selected area. Using the mathematical method of analysis of variance, we came to the conclusion that in all the groups of municipalities, according to the population criteria, the most significant natural disasters were considered to be flooding and landslides. In addition to identifying the most significant natural disasters, preventive measures were proposed. Through a modified method of the decision making matrix (FDMM - Forced Decision Matrix Method), one of the multi-criteria methods indicated the most satisfactory measures which met the established criteria. For floods, flow adjustments and protective reservoirs were the preferred preventive measures. For landslides the preferred preventive measures were slope adjustment and technical stabilization measures. By applying these preventive measures into urban plans for improving the safety of a selected area, the likelihood of a crisis phenomenon and its negative effects will be reduced.

\section{Acknowledgements}

This work was carried out under the grant project - KEGA Project 005 DTI4/2014. The authors would like to thank the Ministry of Education of the Slovak Republic and the Faculty of Security Engineering, University of Zilina for their support.

\section{References}

[1] Územné plány, Územný plán obce, (online). (cit. 2015-03-10). Accessible at: http://www.uzemneplany.sk/upn/plavec/uzemny-plan-obce/navrh/text/ sprievodna-sprava

[2] Zákon č. 42/1994 Z. z. Národnej rady Slovenskej republiky z 27.01.1994 o civilnej ochrane.

[3] Betáková, J., Lorko, M. \& Dvorský J., The impact of the potential risks of the implementation of instruments for environmental area management on the development of urban settlement, Environmental impact II, Ancona, ISBN 978-184564762-9, pp. 91-101, 2014.

[4] Betáková, J., Dvorský, J. \& Havierniková K., Social capital and safety perception as aspect of improving regional competitiveness of territory. 2nd International Conference on Management Innovation and Business Innovation, Bangkok, ISBN 978-981-09-1685-5, pp. 68-73, 2014.

[5] Poledňák, P. \& Orinčák, M., Riešenie prírodných krízových situácií. University of Žilina, Žilina, ISBN 978-80-554-0339-7, p. 232, 2011.

[6] Betáková, J., Lorko, M., \& Dvorský J., Sectional integration of spatial impacts of environmental risks. $6^{\text {th }}$ International Conference on Safety and Security Engineering, Opatija, Croatia, ISBN 978-1-84564-928-9, pp. 15-26, 2015. 
[7] Havierniková, K., \& Skrovnaliková, P., The immunity of family business in the conditions of economic crisis, 2014. In: Problems of social and economic development of business: Collection of scientific articles. Volume I. Montreal: Publishing house Breeze. ISBN 978-1-926711-19-5. pp. 179-183, 2014.

[8] Máca, J. \& Leitner, B. Operačná analýza I. University of Žilina, Žilina. ISBN 80-88829-39-9, p. 191, 1998. 